\title{
Glutamine and glutaminolysis are required for efficient replication of infectious spleen and kidney necrosis virus in Chinese perch brain cells
}

\author{
Xiaozhe Fu ${ }^{1,2,4, *}$, Xianqin Hu${ }^{2,3, *}$, Ningqiu Li $^{1,2}$, Feifei Zheng ${ }^{2}$, Xingxing Dong ${ }^{2}$, \\ Jing Duann', Qiang Lin ${ }^{1,2}$, Jiagang Tu², Lijuan Zhao², Zhibin Huang ${ }^{1}$, Jianguo $\mathrm{Su}^{2,4}$, \\ Li Lin ${ }^{2,5}$ \\ ${ }^{1}$ Pearl River Fisheries Research Institute, Chinese Academy of Fishery Sciences, Key Laboratory of Fishery Drug Development, \\ Ministry of Agriculture, Key Laboratory of Aquatic Animal Immune Technology, Guangdong Provinces, Guangzhou, \\ Guangdong, 510380, China \\ ${ }^{2}$ Department of Aquatic Animal Medicine, Research Center of Marine Biology, College of Fisheries, Freshwater Aquaculture \\ Collaborative Innovation Center of Hubei Province Huazhong Agricultural University, Wuhan, Hubei, 430070, China \\ ${ }^{3}$ School of Animal Sciences and Nutritional Engineering, Wuhan Polytechnic University, Wuhan, Hubei, 430023, China \\ ${ }^{4}$ College of Animal Science and Technology, Northwest A and F University, Shanxi Key Laboratory of Molecular Biology for \\ Aquaculture, Yangling, 712100, China \\ ${ }^{5}$ State Key Laboratory of Marine Resource Utilization in South China Sea, Hainan Provincial Key Laboratory for Tropical \\ Hydrobiology and Biotechnology, College of Marine Science, Hainan University, Haikou 570228, China \\ *These authors contributed equally to the work \\ Correspondence to: Li Lin, email: linli@mail.hzau.edu.cn \\ Ningqiu Li, email: liningq@126.com \\ Keywords: Siniperca chuatsi, ISKNV, glutamine, glutaminolysis, TCA cycle
}

Received: April 24, 2016

Accepted: November 21, 2016

Published: November 29, 2016

\section{ABSTRACT}

Viruses rely on host cellular metabolism for energy and macromolecule synthesis during their replication. Infectious spleen and kidney necrosis virus (ISKNV) causes significant economic losses in the Chinese perch (Siniperca chuatsi) industry worldwide. However, little is known about the relationship between ISKNV replication and cellular metabolism. Using transcriptomic analysis, we observed that glutamine metabolism in Chinese perch brain (CPB) cells is altered during ISKNV infection. Moreover, ISKNV replication was decreased in CPB cells cultured in the glutaminedepleted medium. ISKNV replication was also inhibited in CPB cells cultured in the presence of bis-2-(5-phenylacetamido-1,3,4-thiadiazol-2-yl) ethyl sulfide (an inhibitor of glutaminase), (-)-epigallocatechinmo nogallate (an inhibitor of glutamate dehydrogenase) or L-buthionine sulfoximine (an inhibitor of glutathione synthesis). However, virus replication was rescued by the addition of multiple tricarboxylic acid cycle intermediates, ATP, or glutathione reduced ethyl ester. ATP and reduced glutathione/oxidized glutathione levels were increased in CPB cells infected with ISKNV, but were decreased in CPB cells cultured in glutamine-depleted medium. These results indicate ISKNV infection induces glutaminolysis to accommodate the biosynthetic and energy needs for its efficient virus replication.

\section{INTRODUCTION}

Viruses hijack host cellular machinery to facilitate its own replication. Many viruses, including human cytomegalovirus (HCMV) [1, 2] Kaposi's sarcomaassociated herpesvirus (KSHV) [3], herpes simplex virus 1 (HSV-1) [4], hepatitis C virus (HCV) [5], human immunodeficiency virus (HIV) [6], dengue virus [7], and white spot syndrome virus (WSSV) [8,9], induce multiple cellular metabolic alterations. For example, HCMV upregulates fatty acid synthesis, pyrimidine nucleotide biosynthesis, and glycolysis $[1,2]$. 
Glutamine is an abundant amino necessary generation of energy and synthesis of macromolecules in cells [10]. For energy production, glutamine is initially oxidized to glutamate in a reaction catalyzed by glutaminase. Thereafter, glutamate dehydrogenase (GDH) catalyzes the conversion of glutamate to $\alpha$-ketoglutarate $(\alpha-K G)$, which enters the tricarboxylic acid (TCA) cycle. During glutaminolysis, glutamine provides a variety of important TCA intermediates, including the reduced form of nicotinamide adenine dinucleotide (NADH) for oxidative phosphorylation, succinyl coenzyme A (CoA) for adenosine 5'-triphosphate (ATP) generation, and glutathione precursor (glutamate). Glutamine is also essential for the infection and replication of HIV [11], HCMV [10], and vaccinia virus (VACV) [12]. However, the underlying mechanisms remain unclear.

Infectious spleen and kidney necrosis virus (ISKNV) is the type species of the genus Megalocytivirus in the Iridoviridae family [13], which is highly lethal in Chinese perch (Siniperca chuatsi) and can cause great economic losses $[14,15]$. A survey on the host ranges of ISKNV showed that the virus can infect more than 50 marine and freshwater fish, including the species in the Perciformes, Pleuronectiformes, Clupeiformes, Tetraodontiformes, Myctophiformes, and Mugiliformes orders [16]. At present, ISKNV is one of the most important causative agents of fish disease and is listed by the International Epizootic Office (OIE). However, there is currently no vaccine or no other strategies to effectively prevent ISKNV infection. Therefore understanding the relationship between ISKNV replication and cellular metabolic pathways could pave a new way for effective new prevention strategies against the ISKNV infection. Unfortunately, a global metabolic analysis of cells infected with ISKNV is not available.

To identify alterations of host cellular metabolic pathways during ISKNV infection, we analyzed the transcriptomic profile of healthy and ISKNV-infected CPB cells. Our results show that for efficient ISKNV replication, exogenous glutamine is required to replenish TCA cycle intermediates and the ATP supply and for glutathione synthesis.

\section{RESULTS}

\section{ISKNV infection altered glutamine metabolism}

Glutamine is metabolized to replenish the TCA cycle intermediates, meanwhile produces ATP via glutaminolysis (Figure 1). To investigate the effects of ISKNV infection on glutamine metabolism, we have analyzed the transcriptomic profiling of CPB cells infected by ISKNV [17]. Interestingly, ISKNV could induce the up-regulation of the mRNA expressions of some enzymes involved in glutamate metabolism, TCA cycle, and glutathione metabolism (Table 1), indicating that glutamine metabolic pathways might be altered in CPB cells infected with ISKNV.

\section{Glutamine was not essential for the viability of CPB cells, but it was required for efficient ISKNV multiplication}

The CPB cells were cultured in the DMEM medium without glutamine for 72 hours, and the viability of CPB cells was about $92 \%$ compared with that cultured in glutamine repleted-medium (Figure 2A), indicating that glutamine was not essential for the viability of $\mathrm{CPB}$ within $72 \mathrm{~h}$. To further determine whether the absence of glutamine affected physiological function and resulted in the apoptosis, AnnexinV-FITC/PI staining combined with flow cytometric analysis was used to detect the apoptosis. Compared with control cells cultured with glutamine, lack of glutamine resulted in a slight increase of apoptosis cell percentage from $2.97 \%$ to $7.95 \%$, and a slight decrease of the live cell percentage from $96.14 \%$ to $87.08 \%$ (Figure 2B), indicating that lack of glutamine had no significant effect on the apoptosis and survival of $\mathrm{CPB}$ within $72 \mathrm{~h}$.

Subsequently, we investigated the necessity of glutamine for ISKNV multiplication. As shown in Figure 2C, lack of glutamine reduced the yield of ISKNV around $97.85 \%$. Furthermore, addition of BPTES (an inhibitor of glutaminase) into the glutamine-replete medium reduced ISKNV yield around $96.67 \%$, indicating that glutaminolysis was required for the efficient ISKNV multiplication.

To identify the stage-wise requirement of glutamine in the ISKNV life cycle, we examined the viral mRNA transcription, viral protein synthesis, and virion formation in the CPB cells cultured in the medium supplemented with or without glutamine. It has been shown that ISKNV ORF023 and ORF038 were the immediate early genes, ORF034 and ORF093 were early genes, and ORF006 (major capsid protein gene, MCP) was the late gene of ISKNV [17]. Figure 2D showed that in the CPB cells cultured in glutamine-depleted medium, ORF006 mRNA synthesis was inhibited at either time point postinfection. However, the mRNAs of ORF023, ORF038, ORF034 and ORF093 were increased at 24 hours postinfection (hpi). Subsequently, they were decreased at 36 and $48 \mathrm{hpi}$, indicating that glutamine deprivation altered the viral transcription. Glutaminase is the enzyme which catalyzes the conversion of glutamine to glutamate by glutaminolysis. Therefore, the mRNA of glutaminase was monitored and results showed that it was increased at $24 \mathrm{hpi}$, subsequently was decreased at $36 \mathrm{hpi}$ and $48 \mathrm{hpi}$. The expression pattern of glutaminase was similar to the expressions of immediate early gene and early gene of ISKNV. Next, we examined the ISKNV MCP protein expression. As shown in Figure 2E, MCP synthesis was blocked when ISKNV-infected cells were cultured in glutamine-depleted medium, suggesting that exogenous glutamine was necessary for ISKNV protein synthesis. To further investigate whether glutamine deprivation had an 
Table 1: List of major enzymes involved in glutamine metabolism by transcriptomic analysis of chinese perch brain cells infected with infectious spleen and kidney necrosis virus

\begin{tabular}{|c|c|c|c|}
\hline Pathways & Gene names & $\begin{array}{c}\log 2 \text { Ratio } \\
(24 \mathrm{hV} / 24 \mathrm{hC})\end{array}$ & $\begin{array}{c}\log 2 \text { Ratio } \\
(72 \mathrm{hV} / 72 \mathrm{hC})\end{array}$ \\
\hline \multirow{3}{*}{ glutamate metabolism } & Glutaminase (GLS) & 2.79 & 1.44 \\
\hline & $\begin{array}{l}\text { Glutamate dehydrogenase mitochondrial-like } \\
\text { (GDH) }\end{array}$ & 1.04 & 0.82 \\
\hline & Glutaminase kidney isoform & 11.9 & 1.44 \\
\hline \multirow{4}{*}{ TCA cycle } & Phosphoenolpyruvate carboxykinase (PECK) & 1.20 & 0.73 \\
\hline & $\begin{array}{l}\text { Glucose-6-phosphate 1-dehydrogenase-like } \\
\text { (G6PD) }\end{array}$ & 11.14 & 9.17 \\
\hline & $\begin{array}{l}\text { Isocitrate dehydrogenase [NAD] subunit alpha } \\
\text { (IDH) }\end{array}$ & 11.21 & 7.64 \\
\hline & $\begin{array}{l}\text { Succinate dehydrogenase [ubiquinone] iron- } \\
\text { sulfur subunit (SDH) }\end{array}$ & 1.32 & 0.72 \\
\hline \multirow{3}{*}{$\begin{array}{l}\text { Glutathione } \\
\text { metabolism }\end{array}$} & $\begin{array}{l}\text { 3-hydroxyisobutyrate dehydrogenase } \\
\text { (HIBADH) }\end{array}$ & 1.77 & -0.78 \\
\hline & $\begin{array}{l}\text { Glutamate - cysteine ligase catalytic subunit } \\
\text { (GCLC) }\end{array}$ & 1.34 & 0.28 \\
\hline & Glutathione synthetase-like isoform 1 (GSHB) & 4.05 & -1.14 \\
\hline
\end{tabular}

Note: CPB cells were infected with ISKNV at a MOI of 1. Cells infected with or without ISKNV were harvested at 24 and 72 hpi for transcriptomic analysis. V ISKNV; C, control.

impact on ISKNV maturation, the virion formation was observed by transmission electron microscopy (TEM). Figure $2 \mathrm{~F}$ showed that a large number of ISKNV particles were observed in glutamine-replete infected cells at different stages, but only little immature ISKNV particles were observed in glutamine-depleted infected cells. This result clearly indicated that glutamine was required for ISKNV virion maturation in CPB cells. Taken together, these experiments showed that glutamine was required for ISKNV multiplication.

\section{Glutamine was necessary for ISKNV multiplication via maintaining TCA cycle}

Glutamine is the primary source of carbon for energy homeostasis and biosynthesis in cells. Our transcriptomic results showed that ISKNV could induce multiple metabolic alterations, including up-regulation of the mRNA expressions of some enzymes involved in TCA cycle (Table 1). This prompted us to investigate whether ISKNV-infected cells required glutamine to maintain TCA cycle. Glutamate dehydrogenase (GDH) catalyzes glutamate to $\alpha$-ketoglutarate which enters to TCA cycle [18], and EGCG is a specific inhibitor of $\mathrm{GDH}$ [19]. Figure 3A showed that the viability of CPB cells was $94.26 \%$ in the presence of $10 \mu \mathrm{M}$ EGCG, but viral production was significantly reduced by $81.71 \%$ when cells cultured with glutamine-repleted medium were treated with $10 \mu \mathrm{M}$ EGCG (Figure 3B). Supplement with $\alpha-K G(7 \mathrm{mM})$ in ISKNV-infected cells cultured with glutamine-repleted medium supplemented with EGCG could increase the ISKNV yield by approximately $68.5 \%$ (Figure 3B), indicating that a part of glutamine was catalyzed to $\alpha$-ketoglutarate which entered to TCA cycle to rescue ISKNV production. When TCA cycle intermediate (including $\alpha-\mathrm{KG}$, oxaloacetic acid (OAA), pyruvate, and citric acid) was added to the medium of glutamine-depleted ISKNV-infected cells, respectively, Figure $3 \mathrm{C}$ showed that virus productions in cells cultured in glutamine-depleted medium supplemented with TCA cycle intermediates were significantly higher than that in glutamine-depleted cells. Interestingly, the yield of the virus was increased in the cells cultured in the medium supplemented with citric acid in a dose dependent manner (Figure 3D and 3E). As shown in Figure 3F and 3G, viral MCP expression was suppressed in CPB cells cultured in glutamine-depleted medium, but it was substantially recovered by the additional supplementation of TCA cycle intermediates ( $\alpha-K G$, pyruvate, OAA or citric acid). Taken together, these results showed that exogenous glutamine served as an anaplerotic substrate replenishing the TCA cycle to partly rescue ISKNV production.

\section{Glutamine supported efficient ISKNV multiplication also by supplying ATP}

Besides replenishing the TCA cycle intermediates, glutamine also produces ATP via glutaminolysis. There is growing evidence that ATP is an energy source for maturation and assembly of many enveloped viruses 
$[20,21]$. To investigate whether ISKNV multiplication in CPB cells required glutamine to produce ATP, glutamine or ATP was added to the medium of glutamine-depleted infected cells. CPB cell viability was measured when the cells were cultured in glutamine-depleted medium supplemented with ATP. The result showed that cell viability was not significantly decreased when CPB cells were cultured in glutamine-depleted medium supplemented with additional ATP at 1, 2, 3, 4 mM (about $75 \%$ of that in the glutamine repleted medium). However, it was reduced to about $40 \%$ in glutamine-depleted medium supplemented with additional 5 or $6 \mathrm{mM}$ ATP (Figure 4A). When additional 1 or $4 \mathrm{mM}$ ATP was added to $\mathrm{CPB}$ cells cultured in glutamine-depleted medium, the intracellular ATP levels were significantly increased until 48 hours (Figure 4B), indicating that addition of ATP in the medium could enhance the intracellular ATP concentration. Moreover, when CPB cells were cultured in medium supplemented with glutamine, the intracellular ATP was enhanced (Figure 4C), indicating that addition of glutamine was directly related with the intracellular ATP production. Thus, we further investigated the relationship between the multiplication of ISKNV and intracellular ATP production. The result showed that the addition of ATP was able to increase the yield of ISKNV in the supernatant of CPB cells cultured in glutamine-depleted medium (Figure 4D), indicating that supplying ATP for efficient ISKNV replication was also a role of glutamine.

\section{Glutamine provided substrates for glutathione synthesis to promote ISKNV multiplication}

Glutathione consists of glutamate, cysteine, and glycine. It has been shown that glutathione storage correlated with the loss of glutamine and glutamate, but not with cysteine or glycine $[22,23]$. Thus we examined the influence of glutathione on ISKNV replication. L-Buthionine sulfoximine (BSO) is a specific inhibitor for inhibiting the synthesis of glutamate to glutathione [24]. Figure 5A showed that the CPB cell viability was $95 \%$ in the presence of $2.0 \mathrm{mM}$ BSO. However, viral production was significantly decreased when cells were

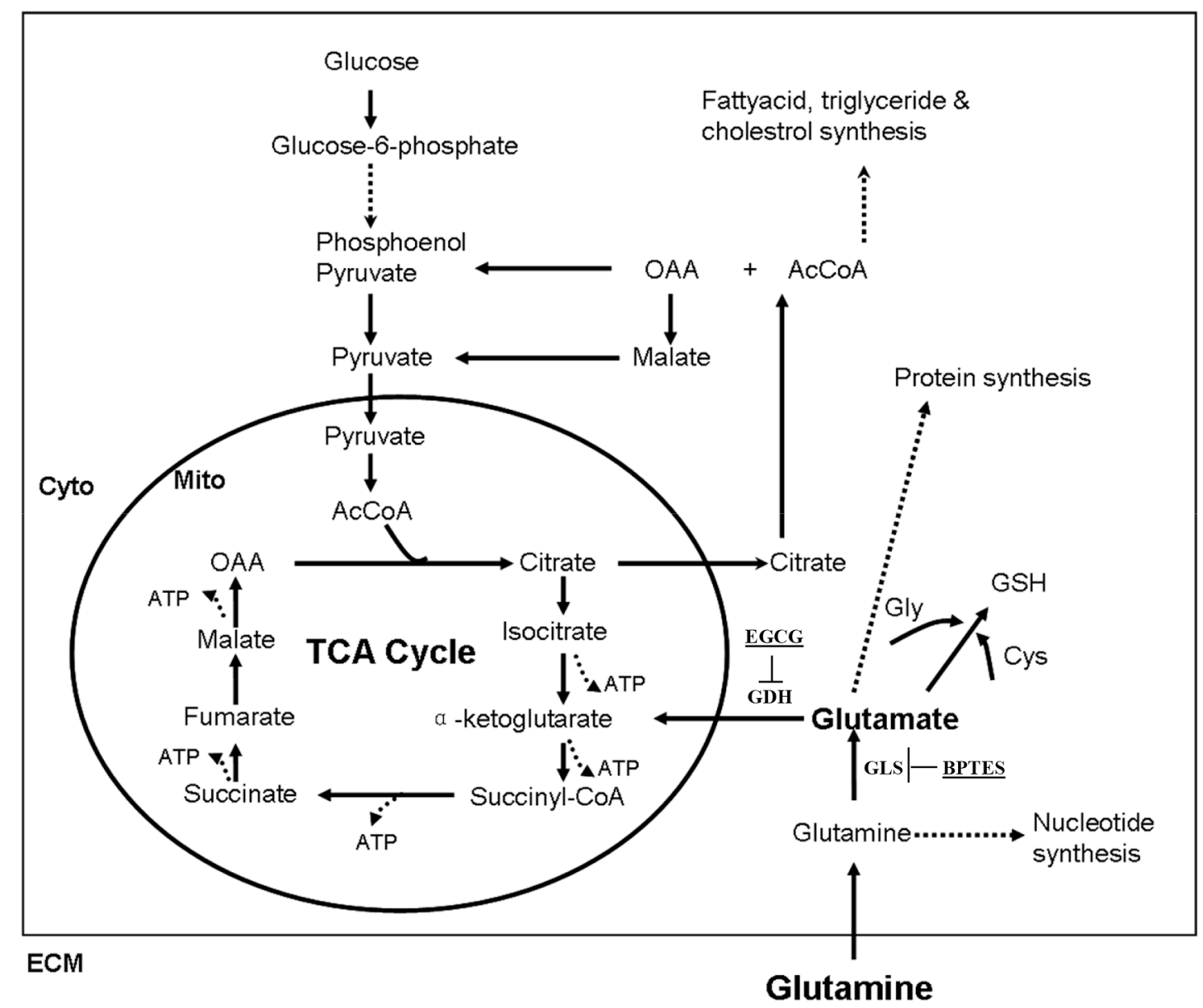

Figure 1: Simplified schematic of glutamine metabolism. Reactions within the box are intracellular, and circle occurs in the mitochondrion (Mito), whereas those outside in the circle occur in the cytoplasm (Cyto). Dashed lines indicate that there are several intermediates formed (several reactions) between the ones shown. Abbreviations: TCA cycle (tricarboxylic acid cycle); OAA (oxaloacetic acid); AcCoA (acetyl coenzyme A); GSH (glutathione); Gly (glycine); Cys (cysteine); ECM (extracellular matrix). 
treated with BSO at $2.0 \mathrm{mM}$, indicating that glutathione synthesis was required for efficient ISKNV replication (Figure 5B). Glutathione is a reduced compound (reduced glutathione, GSH) and serves as a major cellular antioxidant via metabolic inter-conversion with oxidized glutathione (GSSG) [25]. Figure 5C and 5D showed that the amounts of GSH and GSSG in CPB cells infected with ISKNV were increased. GSH ethyl ester (GSHe) is a GSH analog that can be transported across the cell membrane and is converted to free GSH $[26,27]$. In the presence of lower concentrations of GSHe $(0.1-1 \mathrm{mM})$ in the cell medium, the yield of ISKNV was enhanced in CPB cells (Figure 5E). Taken together, these results suggested that ISKNV multiplication needed a certain amount of GSH and glutamine supplied substrate for GSH synthesis.

\section{DISCUSSION}

Viruses have evolved to manipulate host cellular metabolism to support their energetic and biosynthetic requirements for successful replication. Several viruses reportedly alter glutamine metabolism to satisfy the

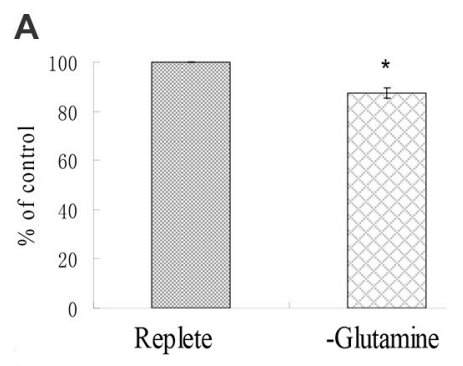

D
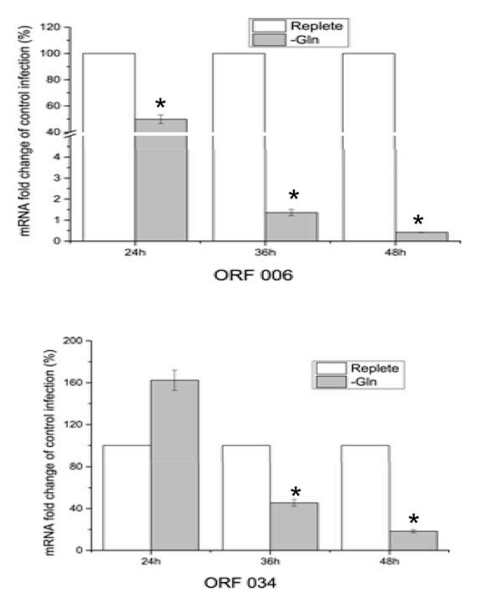

E

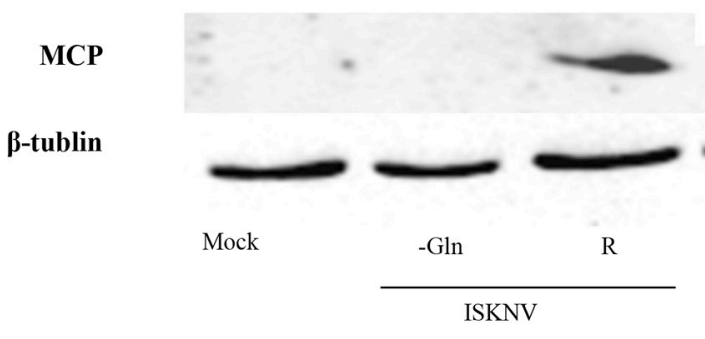

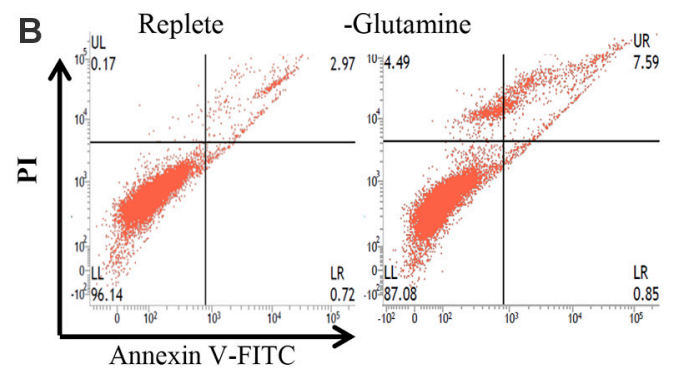

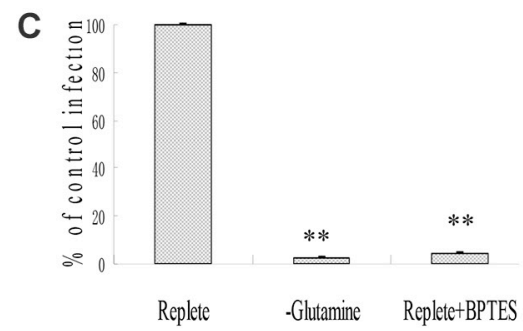

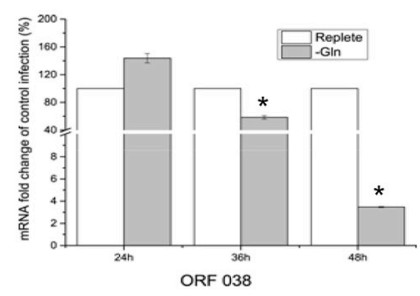
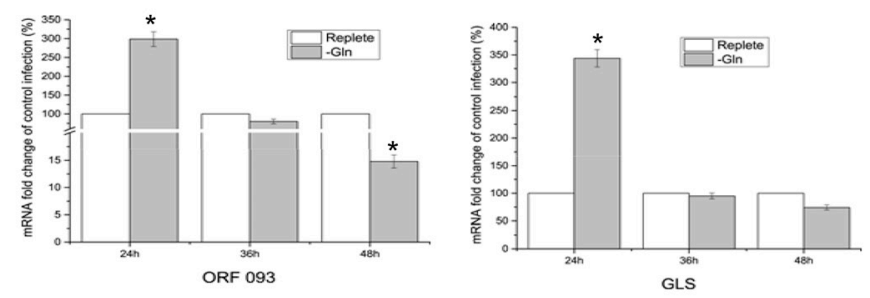

$\mathbf{F}$
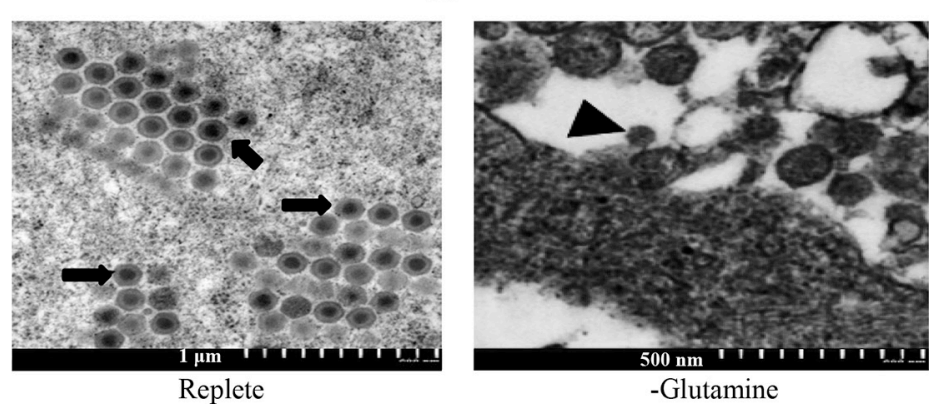

Figure 2: Glutamine is necessary for optimal infectious ISKNV production. (A) Cell viability of CPB. Cells were fed with repleted medium or glutamine-depleted medium, respectively. At $72 \mathrm{~h}$ post treatment, cell viability was measured by MTS assay. (B) Apoptosis of CPB cells. The apoptosis of CPB cells cultured with glutamine or without glutamine for 72 hours was determined by AnnexinV-FITC/PI staining combined with flow cytometry assay. (C) Comparison of viral production. CPB cells were infected with ISKNV at an MOI of 1 and fed replete medium, glutamine-depleted medium, or fed replete medium with $10 \mu \mathrm{M}$ BPTES at 2 hpi. The supernatant was harvested at $72 \mathrm{hpi}$, and viral yields were determined by TaqMan q-PCR. (D) Quantitative real-time RT-PCR analysis of ORF023, ORF038, ORF034, ORF093, ORF006 and GLS transcript levels in ISKNV-infected cells supplemented with or without glutamine. (E) Immunoblot analysis of MCP levels in ISKNV-infected cells fed replete medium (R), or glutamine-depleted medium (-Glu). Lysates from cells harvested at 72 hpi were subjected to western blot analysis using antibodies against MCP and loading control $\beta$-tublin. (F) Transmission electron micrograph analysis of virion formation in ISKNV-infected cells cultured with or without glutamine medium. The arrows show mature virion; the arrow head shows immature virion particles. ${ }^{*} p<0.05 ; * * p<0.01$. 
biosynthetic and energy needs for their replications [10-12]. Our transcriptomic results showed that glutamine metabolism in CPB cells is greatly altered during ISKNV infection. We confirmed that ISKNV replication was inhibited in glutamine-free medium and was rescued by addition of glutamine. Furthermore, ISKNV replication in glutamine-depleted cells was substantially rescued by supplementation with TCA cycle intermediates, including $\alpha-\mathrm{KG}, \mathrm{OAA}$, pyruvate, and citric acid. This suggests that in ISKNV infected cells, glutamine was converted to $\alpha-K G$, which enters the TCA cycle (Figure 1). We also found that the anaplerosis efficiency of citric acid was significantly higher than those of $\alpha-K G, O A A$, and pyruvate. The importance of citric acid generated by glutamine metabolism during ISKNV replication needs to be examined further.

Glutamine can be metabolized to $\alpha-\mathrm{KG}$ to provide ATP through glutaminolysis [28]. Indeed, Chambers et al.
[10] found that glutamine is a crucial nutrient for ATP generation. For example, addition of extra glucose to glutamine-depleted medium did not rescue ATP production during $\mathrm{HCMV}$ infection, indicating that the loss of ATP was due to the lack of glutamine. ATP is an energy source for the binding, maturation, assembly, and budding processes of many enveloped viruses [29]. It is noteworthy that ISKNV ORF123 encodes an ATPase, suggesting ISKNV may require extra ATP for efficient replication. We found that intracellular ATP levels were higher in ISKNV-infected cells than in mock-infected cells, and extracellular ATP increased ISKNV production. Moreover ATP levels and ISKNV yield in glutaminerepleted medium were higher than in glutamine-depleted medium, indicating that glutamine might directly provide ATP for ISKNV multiplication.

Our results also showed that glutamine affects viral transcription, protein translation and virion maturation.
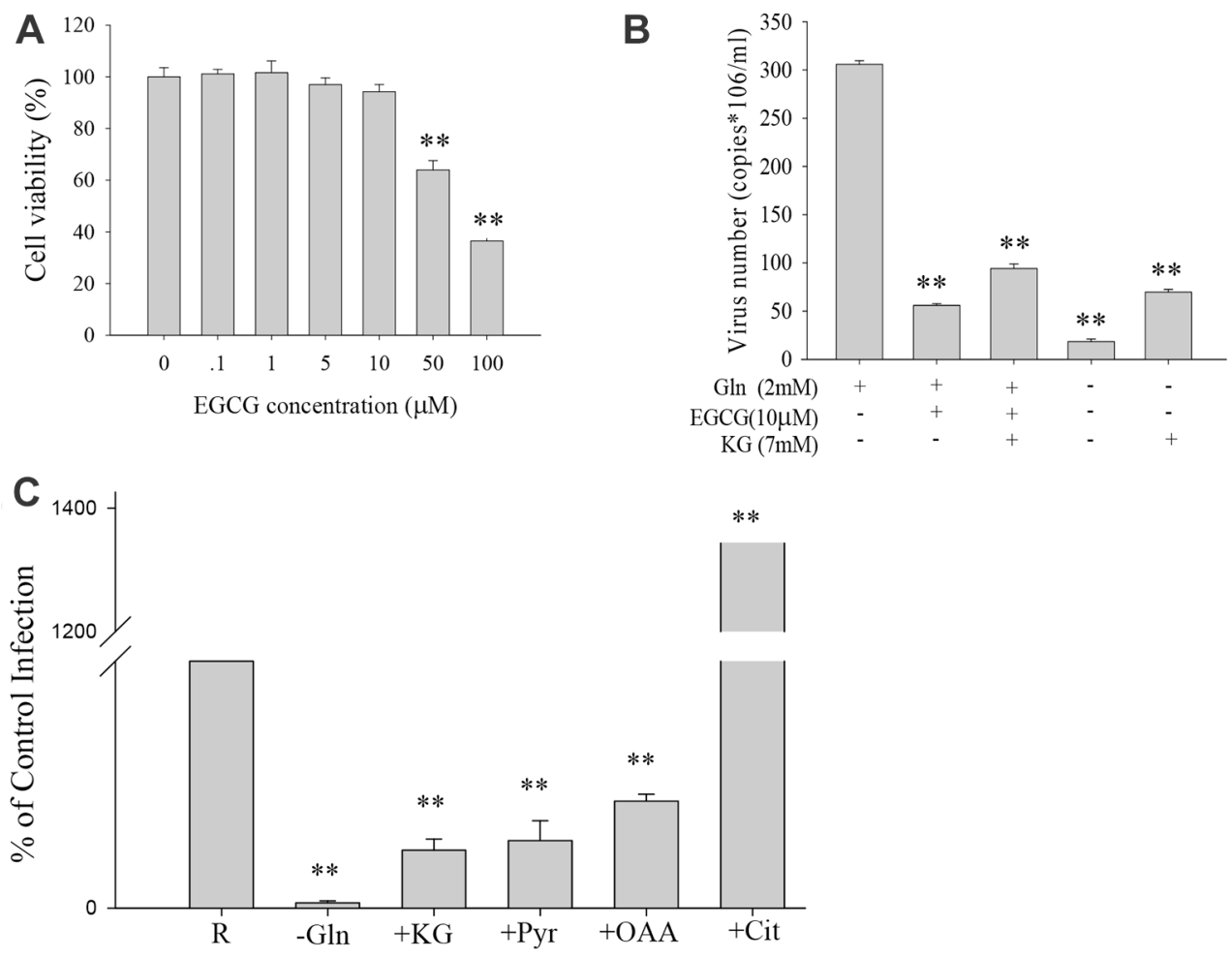

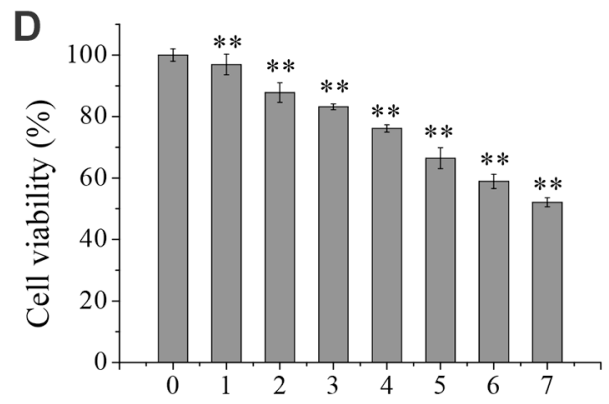

Citric acid concentration (mM)
E

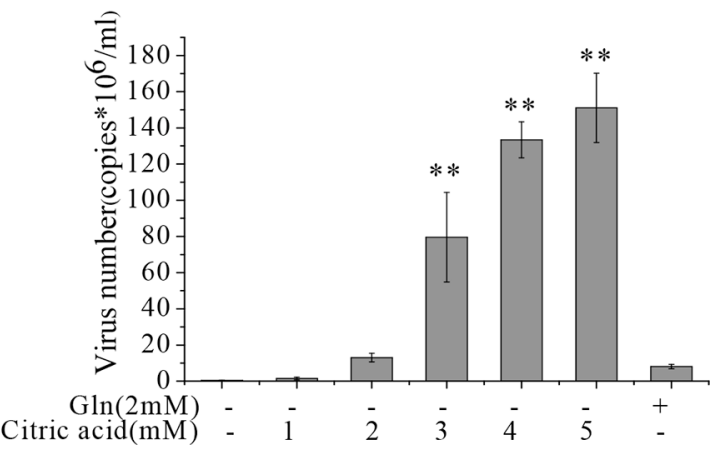




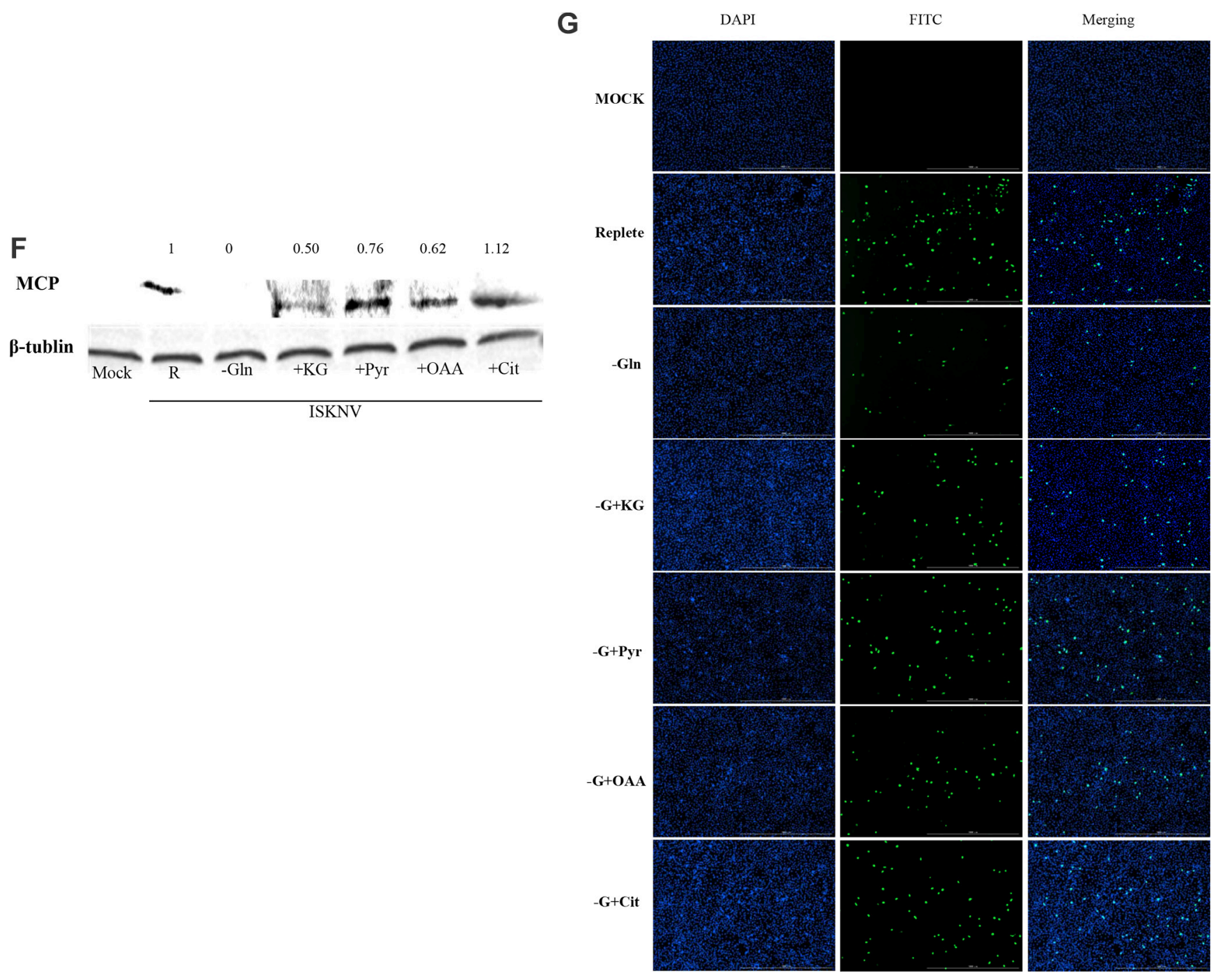

Figure 3: Glutamine is an essential anaplerotic substrate for the TCA cycle during ISKNV infection. (A) CPB cells fed with repleted medium were treated with different concentrations of EGCG for $72 \mathrm{~h}$, and the cell viability was measured by MTS assay. The activity of mock-treated samples was assigned as 100\%. (B) CPB cells were infected with ISKNV at an MOI of 1 and were fed replete medium, or replete medium supplemented with EGCG, or replete medium supplemented with EGCG and 7 mM dimethyl- $\alpha$-ketoglutarate $(\alpha-K G)$, or glutamine-depleted medium (-Glu), or glutamine-depleted medium supplemented with $\alpha-K G$ (7 mM). ISKNV from the cell supernatant was harvested at $72 \mathrm{hpi}$, and viral yield was determined by TaqMan q-PCR. (C) CPB cells were infected with ISKNV at an MOI of 1 and were fed replete medium (R), glutamine-depleted medium (-Glu), or glutamine-depleted medium supplemented with 7 mM dimethyl- $\alpha$-ketoglutarate $(\alpha-\mathrm{KG}), 4 \mathrm{mM}$ pyruvate (Pyr), $4 \mathrm{mM}$ oxaloacetic acid (OAA) or $4 \mathrm{mM}$ citric acid-anhydrous (Cit) at 2 hpi. Cellassociated virus was harvested at $72 \mathrm{hpi}$, and viral yields were determined by TaqMan q-PCR. (D) CPB cells fed with glutamine-depleted medium were treated with different concentrations of citric acid for $72 \mathrm{~h}$, and the cell viability was measured by MTS assay. The activity of mock-treated samples was assigned as 100\%. (E) CPB cells in the presence or absence of glutamine or citric acid were infected with ISKNV at an MOI of 1 at 2 hpi. Cell supernant was harvested at 48 hpi, and viral yield was determined by TaqMan q-PCR. (F) Immunoblot analysis of ISKNV MCP levels in ISKNV-infected cells fed the different medium same as B. Lysates from cells harvested at $72 \mathrm{hpi}$ were subjected to western blot analysis using antibodies against MCP and loading control $\beta$-tublin. The values up the lanes indicated the relative intensity of each major band. (G) Immunofluorecent analysis of MCP levels in ISKNV-infected cells fed the different medium same as C. ${ }^{* *} p<0.01$.

However, we could not determine whether glutamine affects all three of those steps or mainly the transcription step, since transcription step is situated upstream of protein translation and virion maturation. It is noteworthy that transcription of viral immediate early genes and early genes was not decreased (even a little bit increased) at 24 hpi in CPB cells cultured in glutamine-depleted medium. By contrast, transcription of a late gene (MCP gene) was inhibited throughout the course of the infection, indicating that glutamine might activate or suppress expression of viral immediate early genes, early genes and late genes via different mechanisms that remain to be 
elucidated. Interestingly, the pattern of glutaminase gene transcription was similar to that of viral immediate early genes and early genes, which are usually involved in the regulation of viral replication. Although the underlying mechanism is unknown, it is likely that under glutaminedepleted conditions, ISKNV alters not only cellular metabolism but also viral gene expression in order to compensate for the lack of glutamine.

Glutathione plays a prominent role in the defense against oxidative stress. The redox status of cells depends on the ratio of GSH to GSSG. Glutamine can be converted to glutamate, which is a substrate for GSH synthesis [11]. Glutathione synthetase (GSHB) is essential for glutathione synthesis. Our transcriptomic results showed that GSHB was up-regulated at $24 \mathrm{hpi}$ and $72 \mathrm{hpi}$ in CPB cells infected with ISKNV. Furthermore, ISKNV replication was inhibited by BSO, which indicates that glutathione is required for efficient production of ISKNV. Cai et al. [30] found that influenza virus replication is suppressed by GSH within the range of $1-30 \mathrm{mM}$, while it's replication is enhanced when GSH concentration are reduced to $0 \mathrm{mM}$. In our study, ISKNV yield was increased when the GSHe concentration was $0.1-1 \mathrm{mM}$ and was inhibited when GSHe levels were more than $1 \mathrm{mM}$. This indicates that ISKNV multiplication benefits from a low GSH concentration. The GSH/GSSG ratio is reportedly about $100: 1$ in the normal cells, but this ratio can be as low as 1:1 under oxidative stress conditions [31]. Viral infection is often associated with oxidative stress, as an oxidized environment may favor viral infection [33]. The addition of extra GSH to the culture may break the balance between GSH and GSSG and create a redox environment. In this study, 2-10 mM GSHe decreased ISKNV replication, while $0.1-1 \mathrm{mM}$ GSHe increased the virus replication.
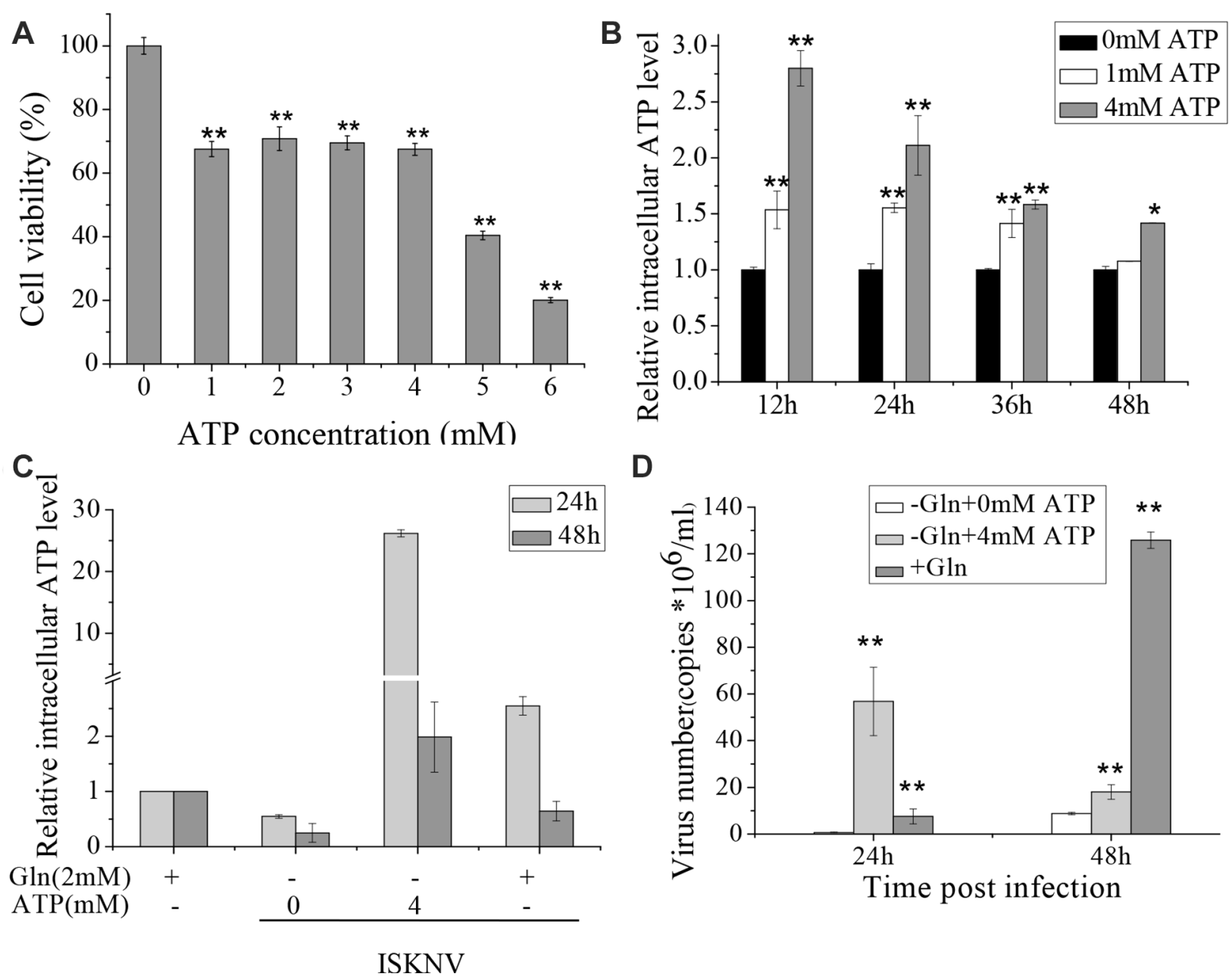

D

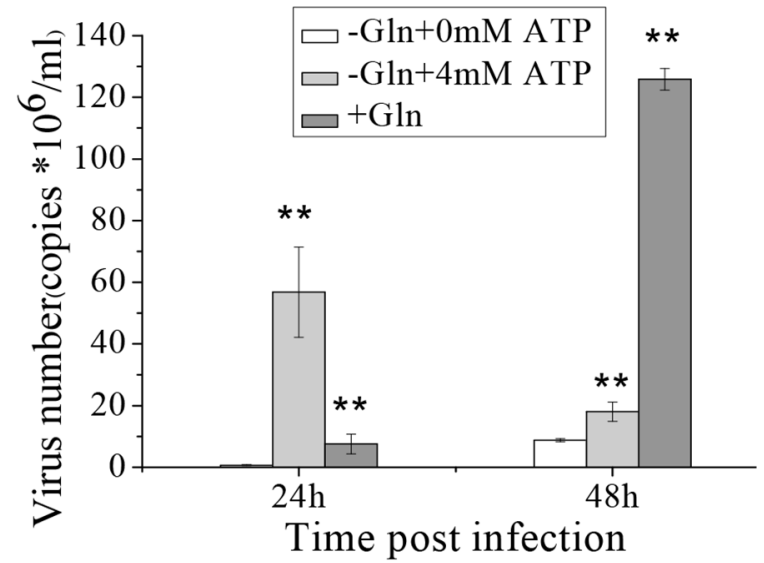

Figure 4: Glutamine provides ATP to induce the rapid ISKNV release. (A) CPB cells fed with glutamine-depleted medium were treated with different concentrations of ATP for $72 \mathrm{~h}$, and the cell viability was measured by MTS assay. The activity of mocktreated samples was assigned as 100\%. (B) Intracellular ATP levels in CPB cells treated with ATP of 0, 1, 4 mM were determined by ATP Colorimetric/Fluorometric Assay Kit. The ATP concentration of mock-treated samples was assigned as 1. (C) Intracellular ATP levels of CPB cells infected with ISKNV at an MOI of 1 at 2 hpi in the presence or absence of glutamine or ATP. Intracellular ATP levels were examined at 24 and $48 \mathrm{hpi}$, and the level of cells without ISKNV infection was set as 1. (D) CPB cells in the presence or absence of glutamine or ATP were infected with ISKNV at an MOI of 1 at 2 hpi. ISKNV of cell supernatant was harvested at 24 and 48 hpi, and viral yield was determined by TaqMan q-PCR. ${ }^{*} p<0.05 ; * p<0.01$. 
This indicates there is an optimal redox environment for efficient ISKNV replication. It is therefore likely that glutathione is involved in oxidative stress activated by ISKNV infection.

In sum, glutamine appears to be required for efficient ISKNV multiplication, as it provides a source for TCA cycle replenishment, ATP generation, and glutathione synthesis. ISKNV replication was inhibited by BPTES and EGCG, suggesting they or their analogs may be promising compounds for prevention of ISKNV infection.

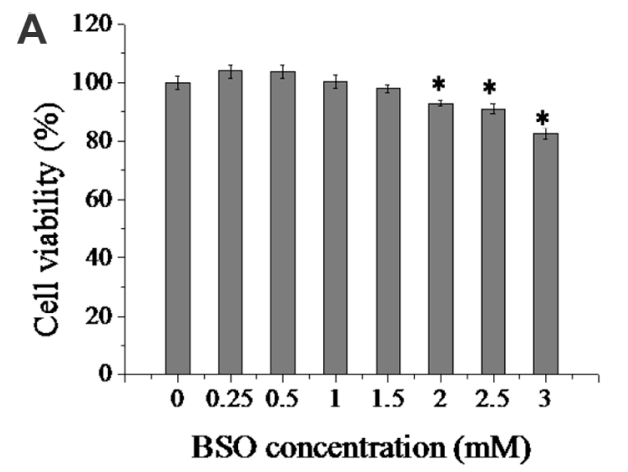

C

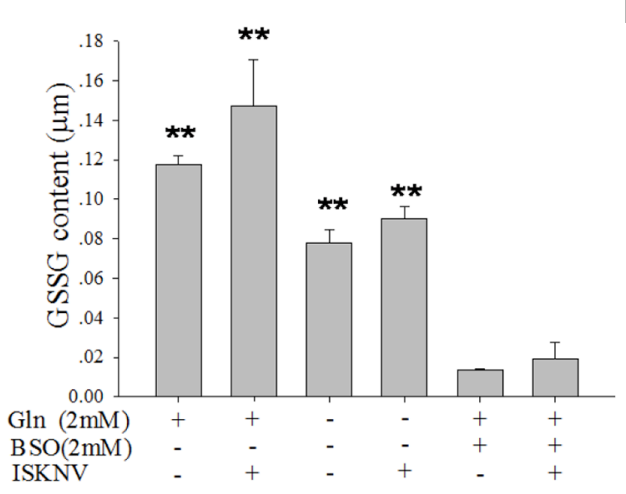

E

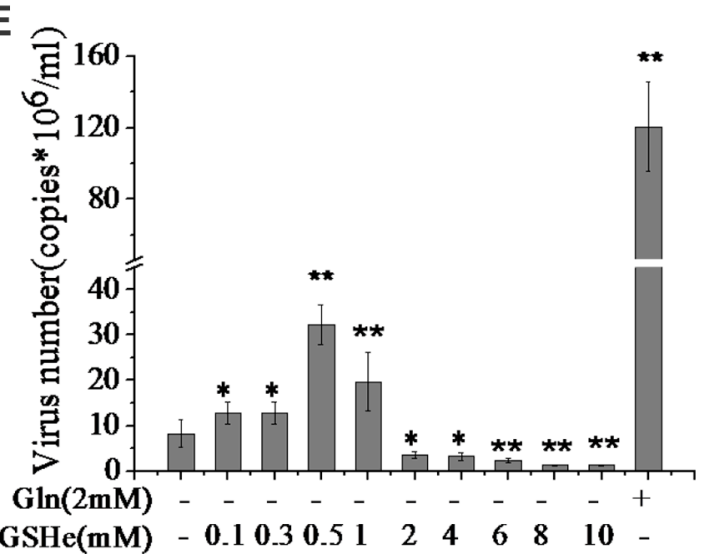

\section{MATERIALS AND METHODS}

\section{Cell lines and virus strains}

Chinese perch brain cells (CPB) were established in our lab [32] and were propagated and maintained at $28^{\circ} \mathrm{C}$ in Leibovitz's L-15 medium (GIBCO, USA) supplemented with $10 \%$ fetal bovine serum (GIBCO, USA). For the glutamine depletion studies, DMEM (GIBCO, USA) with $1 \mathrm{~g} /$ liter D-glucose (Sigma, USA) but lacking
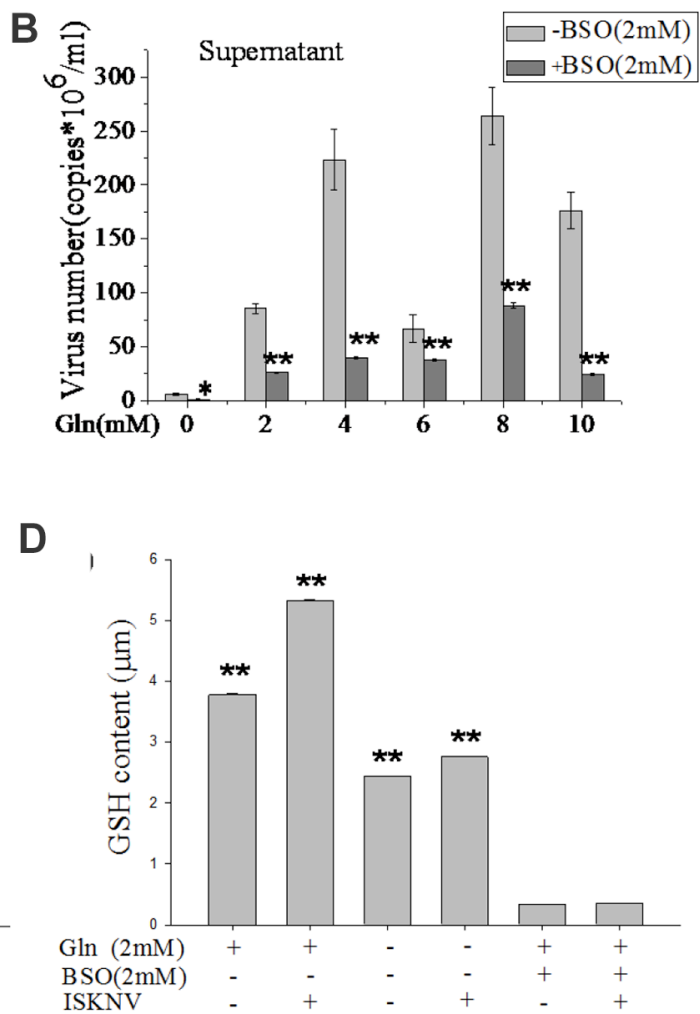
L-glutamine and sodium pyruvate was used. This medium was supplemented with $2 \%$ dialyzed fetal bovine serum (Hyclone, USA), 2 mM L-glutamine (GIBCO, USA) was added and used as replete medium. Infectious spleen and kidney necrosis virus isolate (ISKNV-QY) was isolated in our lab previously [32]. ISKNV was propagated in CPB cells at $28^{\circ} \mathrm{C}$ and its titer was determined by $\mathrm{TCID}_{50}$ assay. The virus was stocked at $-80^{\circ} \mathrm{C}$ until use.

\section{Reagents and antibodies}

Dimethyl- $\alpha$-ketoglutarate $(\alpha-K G)$, (-)-Epigallocatechinmo nogallate (EGCG), oxaloacetic acid (OAA), pyruvate, Adenosine 5'-triphosphate (ATP), citric acid-anhydrous, glutathione reduced ethyl ester (GSHe), and D-(+)-glucose were purchased from SigmaAldrich (USA). L-Buthionine sulfoximine (BSO) was purchased from Santa Cruz Biotechnology (USA). All of above chemicals were diluted with culture medium to the indicated final concentrations just before use. Bis-2(5-phenylacetamido-1,3,4- thiadiazol-2-yl) ethyl sulfide (BPTES) (Sigma, USA) was solubilized in dimethyl sulfoxide (DMSO) to a stock concentration of $10 \mathrm{mM}$. Additional dilutions of BPTES were made in methanol and used at the indicated final concentrations.

\section{Glutamine starvation}

CPB cells grown in replete medium were washed with PBS and infected with ISKNV at an MOI of 1 for $2 \mathrm{~h}$. Subsequently, cells were washed three times with PBS and fed with replete medium or glutamine-depleted medium. For BPTES or EGCG treatment experiment, ISKNVinfected cells were fed with replete medium containing $10 \mu \mathrm{M}$ BPTES or $10 \mu \mathrm{M}$ EGCG. For TCA intermediate rescue studies, TCA cycle intermediates were added to the medium and the final concentration was $7 \mathrm{mM}$ of $\alpha-\mathrm{KG}$, $4 \mathrm{mM}$ of OAA, $4 \mathrm{mM}$ of pyruvate, and $4 \mathrm{mM}$ of citric acid, respectively.

\section{Cell viability assay}

The cytotoxic tests of glutamine-depleted, EGCG, $\mathrm{BSO}$, citric acid, and ATP in CPB cells were performed using the CellTiter $96^{\circledR}$ Aqueous One Solution Cell Proliferation Assay (MTS assay) (Promega, USA). Briefly, cells were seeded $\left(5 \times 10^{4}\right.$ cells/well $)$ in 96-well plates and allowed to attach overnight. Subsequently, these cells were washed with PBS once before fed with $100 \mu$ l glutaminedepleted medium, or glutamine-depleted medium supplemented with EGCG $(0,0.1,1,5,10,50,100 \mu \mathrm{M})$, citric acid (0-7 mM), or ATP (0-6 mM), or BSO $(0,0.25$, $0.5,1,1.5,2,2.5,3 \mathrm{mM})$. At $72 \mathrm{~h}$ post treatment, $20 \mu \mathrm{l}$ of the combined MTS/PMS solution was added into each well, incubated for 3 hours at $28^{\circ} \mathrm{C}$, and then cell viability was determined by recording the $\mathrm{OD}_{490} \mathrm{~nm}$ in an ELISA microplate reader (Infinite M200 Pro, Tecan, Switzerland). Replete medium was used as control.

\section{Apoptosis assay by flow cytometry}

CPB cells were seeded $\left(5 \times 10^{4}\right.$ cells/well $)$ in $25 \mathrm{~cm}^{2}$ culture flasks and allowed to attach overnight. After culture medium was removed, cells were washed with PBS and then cultured in replete medium or glutaminedepleted medium. At $72 \mathrm{~h}$ post treatment, the cells were washed twice with ice cold HBSS, resuspended in $200 \mu \mathrm{l}$ of binding buffer, and stained with AnnexinV-FITC and propidium iodide (PI) following manufacturer's instruction of FITC Annexin V Apoptosis Detection Kit (BD sciences, USA). After incubation for $15 \mathrm{~min}$ in the dark at room temperature, the cells were subjected to flow cytometric analysis (BD FACSVerse flow cytometer). Finally, the percentages of the apoptotic cells were analyzed using BD FACSuite software.

\section{ATP quantitation and ATP rescued experiment}

Intracellular ATP concentrations at 12, 24, $36,48 \mathrm{~h}$ post the addition of exogenous ATP were measured following the instruction of ATP Colorimetric/ Fluorometric Assay Kit (Sigma, USA). Briefly, CPB cells were seeded $\left(5 \times 10^{4}\right.$ cells/well $)$ in $96-$ well plates and allowed to attach overnight. After culture medium was removed, cells were washed with PBS, then lysed in $100 \mu \mathrm{l}$ ATP assay buffer, and incubated on ice for $10 \mathrm{~min}$. The collected mix was centrifuged at 12,000 $\mathrm{g}$ for $3 \mathrm{~min}$ at $4^{\circ} \mathrm{C}$. Ten microliter supernatant was added to the reaction mix used for the determination. The samples from three duplicates in black plates with clear bottoms were analyzed by Infinite M200 Pro using the fluorescence (FLU, $\lambda_{\mathrm{ex}}=535 / \lambda_{\mathrm{em}}=587 \mathrm{~nm}$ ).

For determination of infected cells ATP levels, cells infected with ISKNV were incubated in replete medium or glutamine-depleted medium supplemented with ATP $(0$ or $4 \mathrm{mM})$. The plates were incubated at $28^{\circ} \mathrm{C}$ with $5 \% \mathrm{CO}_{2}$. Intracellular ATP level was measured by ATP Colorimetric/Fluorometric Assay Kit and the copy number of ISKNV were measured by quantitative PCR at 24 and 48 hpi.

\section{Quantification of ISKNV copies}

The supernatants of CPB cells infected with ISKNV were treated with proteinase K (Promega, USA) with the final concentration of $160 \mu \mathrm{g} / \mathrm{ml}$ for 2 hours at $56^{\circ} \mathrm{C}$, followed by incubation at $95^{\circ} \mathrm{C}$ for $10 \mathrm{~min}$, centrifugation at $10000 \mathrm{rpm}$ for $10 \mathrm{~min}$. The centrifuged supernatants were used for q-PCR determination by using Premix Ex TaqTM assay (Takara, China) in an ABI 7500 Real-time Detection System (Applied Biosystems, USA). The used primers and probe were listed in Table 2. 
Table 2: Primers used for quantitative RT-PCR

\begin{tabular}{|c|c|c|c|c|}
\hline Gens names & Genebank numbers & Uses & Primer names & Sequences $\left(5^{\prime}-3^{\prime}\right)$ \\
\hline \multirow{3}{*}{ ISKNV-MCP } & \multirow{3}{*}{ NC_003494.1 } & \multirow{3}{*}{$\begin{array}{l}\text { Quantification } \\
\text { analysis }\end{array}$} & $\mathrm{F}$ & CAATGTAGCACCCGCACTGACC \\
\hline & & & Probe & $\begin{array}{l}\text { FAM-CACCAAACTGACCG } \\
\text { CGGACTCGT-Eclipse }\end{array}$ \\
\hline & & & $\mathrm{R}$ & ACCTCACGCTCCTCGCTTGTC \\
\hline \multirow{2}{*}{ GLS } & \multirow{2}{*}{$\begin{array}{l}\text { Sequence obtained } \\
\text { from transcriptom }\end{array}$} & \multirow{14}{*}{$\begin{array}{l}\text { Transcription } \\
\text { analysis }\end{array}$} & q-GLS-F & TCCTGCGGCATGTACGACTTCT \\
\hline & & & q-GLS-R & CCAGCTTGTCCAGTGGAGGTGA \\
\hline \multirow{2}{*}{ ISKNV-MCP } & \multirow{2}{*}{ NC_003494.1 } & & q-MCP-F & CAATGTAGCACCCGCACTGACC \\
\hline & & & q-MCP-R & ACCTCACGCTCCTCGCTTGTC \\
\hline \multirow{2}{*}{ ISKNV-ORF038 } & \multirow{2}{*}{ NC_003494.1 } & & q-038-F & GGTGGGGCGTGTAAAGCAGG \\
\hline & & & q-038-R & GCGGTTTACTTCAAACAGGTCGG \\
\hline \multirow{2}{*}{ ISKNV-ORF023 } & \multirow{2}{*}{ NC_003494.1 } & & q-023-F & GATGGGAATTGTCATTGGGTCTTG \\
\hline & & & $\mathrm{q}-023-\mathrm{R}$ & CACAGCGGGTGAAACGGAAA \\
\hline \multirow{2}{*}{ ISKNV-ORF034 } & \multirow{2}{*}{ NC_003494.1 } & & q-034-F & CGCACGCACAACGAGACCA \\
\hline & & & q-034-R & TCCTCGGAGACGCCCAGTG \\
\hline \multirow{2}{*}{ ISKNV-ORF093 } & \multirow{2}{*}{ NC_003494.1 } & & q-093-F & GAGTGCATGTCGATATGGTGGCA \\
\hline & & & q-093-R & TGGCGTAGTTGGGGTGTTGGA \\
\hline \multirow{2}{*}{ 18s RNA } & \multirow{2}{*}{ AY452495.1 } & & q-18s-F & CATTCGTATTGTGCCGCTAGA \\
\hline & & & $q-18 s-R$ & CAAATGCTTTCGCTTTGGTC \\
\hline
\end{tabular}

The copy numbers of ISKNV was calculated by comparison to the standard curve as described previously [33].

\section{Transcription of genes during ISKNV infection}

The transcriptional levels of GLS and MCP genes were evaluated by quantitative reverse transcription PCR assays (qRT-PCR). Total RNAs were isolated from the cells at 72 hpi with TRIzol reagent (Invitrogen, USA), and then treated with RNase-free DNaseI (Promega, USA). The RNA was dissolved in $20 \mu$ of RNase-free water and stored at $-70^{\circ} \mathrm{C}$ until used. The amount of $1 \mu \mathrm{g}$ RNA was used for reverse transcription to cDNA using RevertAid $^{\mathrm{TM}}$ First Strand cDNA Synthesis Kit (Fermentas, CAN). The qRT-PCR was carried out in an ABI 7500 Real-time Detection System (Applied Biosystems, USA) using Maxima SYBR Green/ROX qPCR Master Mix (Fermentas, CAN). All PCR amplification reactions were performed in a volume of $20 \mu \mathrm{l}$, containing $0.8 \mu \mathrm{l} \mathrm{cDNA}$, $0.3 \mu \mathrm{l}$ of each primer $(10 \mu \mathrm{M}), 2 \times$ Master Mix $10 \mu \mathrm{l}$. PCR conditions were as follows: $10 \mathrm{~min}$ at $95^{\circ} \mathrm{C}$, followed by 40 cycles of $15 \mathrm{~s}$ at $95^{\circ} \mathrm{C}, 30 \mathrm{~s}$ at $60^{\circ} \mathrm{C}$ and $15 \mathrm{~s}$ at $72^{\circ} \mathrm{C}$. Then at $95^{\circ} \mathrm{C}$ for $15 \mathrm{~s}, 60^{\circ} \mathrm{C}$ for $1 \mathrm{~min}, 95^{\circ} \mathrm{C}$ for $15 \mathrm{~s}$. Melting curve was used to confirm the specificity of qRT-PCR amplification. The gene expression level was analyzed using comparative threshold cycle method $\left(2^{-\triangle \Delta C T}\right)$ with $18 \mathrm{sRNA}$ gene as an internal control. The primers have been listed in Table 2. All data were given in terms of relative mRNA.

\section{Immunofluorescence assay}

Cells were fixed with methanol for $20 \mathrm{~min}$ at room temperature and rinsed with PBS twice. Cells were incubated with the primary anti-MCP sera (1:200) for $1 \mathrm{~h}$ at room temperature, followed by three PBS washes. Then cells were incubated with the secondary fluorescein isothiocyanate (FITC)-conjugated goat antimouse IgG monoclonal antibody (1:100) (CWBIO, China) for $1 \mathrm{~h}$ at room temperature, followed by DAPI (2, 4-diamidino-2-phenylindole) (Beyotime, China) staining at a concentration of $1 \mathrm{mg} / \mathrm{ml}$ for $2 \mathrm{~min}$ at room temperature and washed thrice with PBS. The FITC signal was detected with an inverted fluorescence microscope (Nikon, Japan), and the images were captured by a digital imaging system (Nikon, Japan).

\section{Western blot analysis}

CPB cells were collected and lysed in RIPA buffer with $1 \mathrm{mM}$ PMSF. Proteins were separated by $12 \%$ SDSPAGE and transferred onto Immobilon P polyvinylidene difluoride membranes (Millipore, USA). Blots were incubated with the indicated primary antibody, anti-ISKNV MCP (1:1000 dilution), anti-tubulin (1:5000 dilution), and subsequently incubated with peroxidase-conjugated goatanti-rabbit $\operatorname{IgG}$ (1:5000 dilution). Immunoreactive proteins were visualized by chemiluminescence using Thermo Scientific Pierce Western Blot ECL Plus (Thermo, USA). 


\section{Transmission electron microscopy}

CPB cells with the confluency of $80-90 \%$ were infected with ISKNV at an MOI of 1 and fed with replete medium, or glutamine-depleted medium for $72 \mathrm{~h}$. The infected cells were fixed with $2.5 \%$ glutaraldehyde in $0.1 \mathrm{M}$ phosphate buffer $(\mathrm{pH} 7.4)$ for $24 \mathrm{~h}$ at $4^{\circ} \mathrm{C}$ and then post-fixed in $0.1 \mathrm{M}$ phosphate buffer containing $1 \%$ osmium tetroxide for $1 \mathrm{~h}$. Ultrathin sections were stained with uranyl acetate-lead citrate and examined by a Philips CM10 electron microscopy.

\section{Statistical analysis}

Data were reported as mean \pm standard deviation and analyzed using one-way analysis of variance (one-way ANOVA) followed by Fisher's LSD test using SPSS 17.0. $p<0.05$ was considered significant and indicated by an asterisk while $p<0.01$ was indicated by a double asterisks in the Figures.

\section{ACKNOWLEDGMENTS AND FUNDING}

This study was jointly supported by the National Natural Science Fund (No. 31502201, 31572657, 31372563), Special funds from Administration of Ocean and Fisheries of Guangdong Province (A201501B12, A201512C003, 2015-006, 2015-115); Special fund from Hubei Province (2015BBA228); National Key Technology R\&D Program (2012BAD25B02); Fund from Wuhan Science and Technology Bureau (2016020101010089) and Fundamental Research Funds for the Central Universities (2014PY035).Thanks for Drs. Farman Ullah Dawar and Muhammad Asim for the proof-reading of the manuscript.

\section{CONFLICTS OF INTEREST}

The authors have no conflicts of interest to report.

\section{REFERENCES}

1. Munger J, Bajad SU, Coller HA, Shenk T, Rabinowitz JD. Dynamics of the cellular metabolome during human cytomegalovirus infection. PLoS Pathog. 2006;2:e132.

2. Munger J, Bennett BD, Parikh A, Feng XJ, McArdle J, Rabitz HA, Shenk T, Rabinowitz JD. Systems-level metabolic flux profiling identifies fatty acid synthesis as a target for antiviral therapy. Nat Biotechnol. 2008; 26:1179-1186.

3. Delgado T, Sanchez EL, Camarda R, Lagunoff M. Global metabolic profiling of infection by an oncogenic virus: $\mathrm{KSHV}$ induces and requires lipogenesis for survival of latent infection. PLoS Pathog. 2012;8:e1002866.

4. Vastag L, Koyuncu E, Grady SL, Shenk TE, Rabinowitz JD. Divergent effects of human cytomegalovirus and herpes simplex virus-1 on cellular metabolism. PLoS Pathog. 2011;7:e1002124.

5. Diamond DL, Syder AJ, Jacobs JM, Sorensen CM, Walters KA, Proll SC, McDermott JE, Gritsenko MA, Zhang Q, Zhao R, Metz TO, Camp DG, Waters KM, et al. Temporal proteome and lipidome profiles reveal hepatitis $\mathrm{C}$ virus-associated reprogramming of hepatocellular metabolism and bioenergetics. PLoS Pathog. 2010;6:e1000719.

6. Hollenbaugh JA, Munger J, Kim B. Metabolite profiles of human immunodeficiency virus infected CD4+ T cells and macrophages using LC-MS/MS analysis. Virology. 2011; 415:153-159.

7. Birungi G, Chen SM, Loy BP, Ng ML, Li SF. Metabolomics approach for investigation of effects of dengue virus infection using the EA.hy926 cell line. J Proteome Res. 2010; 9:6523-6534.

8. Chen IT, Aoki T, Huang YT, Hirono I, Chen TC, Huang JY, Chang GD, Lo CF, Wang HC. White spot syndrome virus induces metabolic changes resembling the warburg effect in shrimp hemocytes in the early stage of infection. J Virol. 2011; 85:12919-12928.

9. Hsieh YC, Chen YM, Li CY, Chang YH, Liang SY, Lin SY, Lin CY, Chang SH, Wang YJ, Khoo KH, Aoki T, Wang HC. To complete its replication cycle, a shrimp virus changes the population of long chain fatty acids during infection via the PI3K-Akt-mTOR-HIF1 $\alpha$ pathway. Dev Comp Immunol. 2015; 53:85-95.

10. Chambers JW, Maguire TG, Alwine JC. Glutamine metabolism is essential for human cytomegalovirus infection. J Virol. 2010; 84:1867-1873.

11. Porcheray F, Léone C, Samah B, Rimaniol AC, DereuddreBosquet N, Gras G. Glutamate metabolism in HIV-infected macrophages: implications for the CNS. Am J Physiol Cell Physiol. 2006; 291:618-626.

12. Fontaine KA, Camarda R, Lagunoff M. Vaccinia virus requires glutamine but not glucose for efficient replication. J Virol. 2014; 88:4366-4374.

13. Wu SQ, Li XH, Pan HJ, Huang ZB. Research on the pathogen of the outbreak-infective disease of Siniperca chuatsi. Journal of Fisheries of China. 1997; 21:56-60.

14. He JG, Weng SP, Zeng K, Huang ZJ. Identification of outbreak and infectious diseases pathogen of Siniperca chuatsi. acta Scientiarum Naturalium Universitatis Sunyatseni. 1998; 25-31.

15. Chinchar VG, Essbauer S, He JG, Hyatt A, Miyazaki T, Seligy V, Williams T. Virus Taxonomy, VIIIth Report of the International Committee on Taxonomy of Viruses. London, Elsevier/Academic Press, 2005.

16. Fu XZ, Li NQ, Liu LH, Lin Q, Wang F, Lai YT, Jiang HM, Pan HJ, Shi CB, Wu SQ. Genotype and host range analysis of infectious spleen and kidney necrosis virus (ISKNV). Virus Genes. 2011; 42:97-109.

17. Hu XQ, Fu XZ, Li NQ, Muhammad A, Dong XX, Yi LZ, Zhou WD, Ai TS, Yu YZ, Wu SQ, Lin L. Transcriptome 
analysis of chinese perch brain cells infected with infectious spleen and kidney necrosis virus with an emphasis on rlrs and apoptosis pathways. Fish Shellfish Immunol. 2015; 45:612-629.

18. Li M, Smith CJ, Walker MT, Smith TJ. Novel inhibitors complexed with glutamate dehydrogenase: allosteric regulation by control of protein dynamics. J Biol Chem. 2009; 284:22988-23000.

19. Whitelaw BS, Robinson MB. Inhibitors of glutamate dehydrogenase block sodium-dependent glutamate uptake in rat brain membranes. Front Endocrinol (Lausanne). 2013; 4:123.

20. Ericsson M, Sodeik B, Locker JK, Griffiths G. In vitro reconstitution of an intermediate assembly stage of vaccinia virus. Virology. 1997; 235:218-227.

21. Chi JH, Wilson DW. ATP-Dependent localization of the herpes simplex virus capsid protein VP26 to sites of procapsid maturation. J Virol. 2000; 74:1468-1476.

22. Humbert B, Nguyen P, Martin L, Dumon H, Vallette G, Maugère $P$, Darmaun D. Effect of glutamine on glutathione kinetics in vivo in dogs. J Nutr Biochem. 2007; 18:10-16.

23. Hammarqvist F, Luo JL, Cotgreave IA, Andersson K, Wernerman J. Skeletal muscle glutathione is depleted in critically ill patients. Crit Care Med. 1997; 25:78-84.

24. Griffith OW, Meister A. Potent and specific inhibition of glutathione synthesis by buthionine sulfoximine (S-nbutyl homocysteine sulfoximine). J Biol Chem. 1979; 254:7558-7560.

25. Robert SM, Ogunrinu-Babarinde T, Holt KT, Sontheimer H. Role of glutamate transporters in redox homeostasis of the brain. Neurochem Int. 2014; 73:181-191.
26. Anderson ME. Glutathione: an overview of biosynthesis and modulation. Chem Biol Interact. 1998; 111-112:1-14.

27. Priya S, Nigam A, Bajpai P, Kumar S. Diethyl maleate inhibits MCA+TPA transformed cell growth via modulation of GSH, MAPK, and cancer pathways. Chem Biol Interact. 2014; 219:37-47.

28. Oronsky BT, Oronsky N, Fanger GR, Parker CW, Caroen SZ, Lybeck M, Scicinski JJ. Follow the ATP: tumor energy production: a perspective. Anticancer Agents Med Chem. 2014; 14:1187-1198.

29. Liang Y, Xu ML, Wang XW, Gao XX, Cheng JJ, Li C, Huang J. ATP synthesis is active on the cell surface of the shrimp Litopenaeus vannamei and is suppressed by WSSV infection. Virol J. 2015;12:49.

30. Cai J, Chen Y, Seth S, Furukawa S, Compans RW, Jones DP. Inhibition of influenza infection by glutathione. Free Radic Biol Med. 2003; 34:928-936.

31. Pastore A, Federici G, Bertini E, Piemonte F. Analysis of glutathione: implication in redox and detoxification. Clin Chim Acta. 2003; 333:19-39.

32. Fu XZ, Li NQ, Lai YT, Luo X, Wang Y, Shi CB, Huang ZB, Wu SQ, Su J. A novel fish cell line derived from the brain of Chinese perch Siniperca chuatsi: development and characterization. J Fish Biol. 2015; 86:32-45.

33. Fu XZ, Li NQ, Lin Q, Shi CB, Wu SQ. qPCR method for virus titer testing of infectious spleen and kidney necrosis virus, Journal of fisheries of China. 2014; 38:1573-1578. 